\title{
Viral homologs of BCL-2: role of apoptosis in the regulation of virus infection
}

\author{
Andrea Cuconati ${ }^{1}$ and Eileen White ${ }^{1,2,3,4}$ \\ ${ }^{1}$ Howard Hughes Medical Institute, Center for Advanced Biotechnology and Medicine, ${ }^{2}$ Department of Molecular Biology \\ and Biochemistry, Rutgers University, and ${ }^{3}$ Cancer Institute of New Jersey, Piscataway, New Jersey 08854, USA
}

Cellular BCL-2-related proteins (cBCL-2s) function as regulators of programmed cell death (apoptosis), in part by modulating the release of proapoptotic signaling molecules from mitochondria. These factors act to promote activation of cysteine proteases of the caspase family and thereby propagate signaling of apoptotic cell death. DNA viruses are known to encode homologs of cellular antiapoptotic BCL-2 proteins (vBCL-2s), and the role of vBCL-2s in various aspects of viral infection and the mechanism by which they function have been gradually emerging. It is now apparent that inhibition of apoptosis by vBCL-2s in infected cells can prevent premature death of the host cell, which would impair virus production; can enable efficient emergence from latency; can facilitate persistent infection; and contributes to the avoidance of immune surveillance by the host. Thus, apoptosis is clearly a mechanism used by the host immune system and the infected host cell itself as part of the antiviral response. Deregulation of this delicate hostpathogen interaction can alter the course of virus replication, which may explain aspects of viral disease. Recent evidence suggests that vBCL-2s may target the core cellular proapoptotic machinery for inhibition, perhaps to secure a broad spectrum of apoptosis inhibition to the infected cell. Furthermore, because vBCL-2 family members and some of their cellular counterparts are oncogenic, deciphering their mode of action may be useful in understanding and thwarting human cancer. In this review we outline the role and the mechanism of action of vBCL-2 proteins in infected cells and how and why their function may be distinct from some of their cellular homologs.

\section{Identification of vBCL-2s}

The first indication that viruses encode BCL-2 functional homologs and that their manipulation of apopto-

${ }^{4}$ Corresponding author.

E-MAIL ewhite@cabm.rutgers.edu; FAX (732) 235-5795.

Article and publication are at http://www.genesdev.org/cgi/doi/10.1101/ gad.1012702. sis is a requirement for normal productive infection came from observations made with adenovirus-infected cells. One of the oncogenes of adenovirus, E1B 19K, was shown to be required to prevent the degradation of hostcell and viral DNA and enhanced cytopathic effects during productive virus infection (Pilder et al. 1984; Subramanian et al. 1984; Takemori et al. 1984; White et al. 1984). These activities bore a striking resemblance to apoptosis and suggested that the E1B $19 \mathrm{~K}$ protein may function as an apoptosis inhibitor in productively infected human cells (White et al. 1991). At that time, BCL-2 was known to function by promoting cell survival, which was the first link to the genetic pathway of apoptosis regulation in mammalian cells (Vaux et al. 1988). We now know that the function of antiapoptotic cBCL-2s is required for normal development, and an inappropriate gain-of-function mutation is associated with promotion of human cancer. BCL-2 is the prototypical member of a family of proteins that act to regulate apoptosis in a process that is evolutionarily conserved from humans to flies and nematodes (Gross et al. 1999a). That viruses should have stolen or copied this activity to serve their own ends should not be surprising.

E1B 19K and BCL-2 can functionally substitute for one another in the suppression of apoptosis during virus infection and oncogenic transformation, indicating that viruses did, indeed, see fit to encode inhibitors of apoptosis (Rao et al. 1992; White et al. 1992; Tarodi et al. 1993; Chiou et al. 1994b; Subramanian et al. 1995). Although the sequence homology between E1B $19 \mathrm{~K}$ and BCL-2 is extremely weak, the most conserved residues in the dozen or so viral serotypes in which the sequence of E1B $19 \mathrm{~K}$ is known are also conserved in BCL-2 (Tarodi et al. 1993; Chiou et al. 1994b). The presence of both sequence and functional homology between E1B 19K and BCL-2 indicates that E1B $19 \mathrm{~K}$ is an adenovirus BCL-2 homolog. Furthermore, the E1B 19K protein also blocks apoptosis induced by a wide variety of stimuli even outside the context of virus infection, indicating that it is functioning at a regulatory point shared by many apoptotic pathways (White 2001). The task then was to determine why adenoviruses encoded an antiapoptotic gene product, and how it worked. A prediction was that if inhibition of 
apoptosis were important for the life cycle of one virus, that it might be an important activity of other viruses. Indeed, the $\gamma$-herpesvirus Epstein-Barr virus (EBV) is recognized to encode a viral homolog of BCL-2, BHRF1 (Cleary et al. 1986; Henderson et al. 1993). It is now known that not only adenoviruses, but also other $\gamma$-herpesviruses (Rabizadeh et al. 1993; Russo et al. 1996; Nicholas et al. 1997; Virgin et al. 1997; Afonso et al. 2001; Rivailler et al. 2002), and the pox-related viruses fowlpox (FPV; Afonso et al. 2000) and African swine fever virus (ASFV; Afonso et al. 1996; Brun et al. 1996) all encode vBCL-2s. These viruses additionally encode alternate, non-BCL-2-type, partially redundant functions to block apoptosis, which underscores the importance of apoptosis inhibition during viral infection (Roulston et al. 1999|. These non-BCL-2-type antiapoptotic functions are apparently sufficient for disabling apoptosis by many other viruses that lack vBCL-2s. We can only conclude that regulating apoptosis during infection is a high priority for many viruses, and one recurring theme is to use a BCL-2-like mechanism to do so.

\section{Virus infection and a need to encode vBCL-2s}

Infection in vitro with proapoptotic mutant adenoviruses that lack E1B 19K function is associated with impaired virus production, indicating that it might be advantageous to the virus to disable apoptosis to facilitate replication during productive infection. This may be necessary because virus-dependent deregulation of cell cycle control initiates an act of altruistic cell suicide on the part of the individual infected cell, which the virus may benefit from inhibiting to sustain host cell viability to enable viruses to maximally replicate. As the immune response to viral infection includes multiple mechanisms for induction of apoptosis of infected cells, inhibition of apoptosis could allow virus replication even when infected cells are under immune attack, thereby contributing to the repertoire of viral immune stealthing functions. Furthermore, inhibition of apoptosis may enable viruses to establish latency, or facilitate the emergence from latency and the establishment of a chronic, persistent infection. Swift and efficient induction of apoptosis upon infection could restrict the host range of virus replication, or facilitate rapid virus release and cellto-cell spread of virus. Finally, an altered apoptotic state of the infected host cell itself, owing to disease or cell type, could promote or diminish virus replication. How and when apoptosis regulation is important to a virus may depend on the specific aspects of the virus life cycle. In this review, we discuss what is known about vBCL-2 function in adenoviruses, herpesviruses, and poxviruses.

\section{Adenoviruses}

The Adenoviridae constitutes a large family of small DNA tumor viruses that have mammal and bird hosts (Horwitz 2001; Shenk 2001). Human adenoviruses are pathogens, some of which are the cause of as much as $10 \%$ of all childhood pneumonias, whereas others cause conjunctivitis and outbreaks of acute respiratory disease. Of the human adenoviruses, there are 51 different serotypes that mainly infect and replicate in epithelial cells of the respiratory and gastrointestinal tract, where they cause mild to severe disease in immunocompetent individuals that can become fatal in those who are immunocompromised. Following the initial acute infection, adenovirus is shed for many months after individuals are symptomatic, suggesting that the virus can establish a persistent infection. Adenovirus encodes numerous immune stealthing functions, including several antiapoptotic activities that may facilitate the establishment of a persistent infection. There is also evidence of the presence of adenoviral DNA without infectious virus in human tissues, particularly lymphocytes, which is indicative of latent infection. Further evidence of persistent or latent adenovirus infections comes from immunosuppressed individuals, who apparently become reinfected, often fatally, from an endogenous source or from a donor organ. Unfortunately, there is no animal model that faithfully reproduces adenovirus disease in humans, although infection of cotton rats or mice that are semi- or nonpermissive for virus replication can recapitulate some of the aspects of human adenovirus disease.

Productive adenovirus infection of the human epithelial cell line HeLa, which is a model system for productive replication, begins with virus entry and early gene expression. E1A expression, in particular, is required to stimulate the transcription of the other viral early genes, and to create an S-phase-like environment for viral DNA replication to proceed. Adenovirus gene products are typically multifunctional, often by having multiple binding sites for the cellular proteins whose activities they modulate. In this way, an adenovirus can retain a fairly small genome $(35 \mathrm{~kb})$ without encoding direct sequence homologs of cellular genes. However, the E1B $19 \mathrm{~K}$ protein may be an exception, as it appears to be a stripped-down, minimal version of cBCL-2s. There are, however, distinct differences between E1B 19K and other vBCL-2s and cBCL-2s.

The product of the adenovirus $E 1 A$ oncogene deregulates the normal cellular constraints of cell cycle regulation by interacting with the retinoblastoma protein (RB), its relatives p107 and p130, and the transcriptional coactivators p300 and CBP. These activities of E1A also activate apoptosis that is inhibited by expression of the products of the $E 1 B$ gene. E1B $55 \mathrm{~K}$, in cooperation with E4 ORF6, interacts with and promotes the degradation of p53 in the proteasome (Querido et al. 2001), whereas the E1B 19K protein blocks apoptosis induced by E1A and also that signaled by death receptor ligands such as tumor necrosis factor- $\alpha$ (TNF- $\alpha)$, Fas ligand (FasL), and tumor necrosis factor- $\alpha$-related apoptosis-inducing ligand (TRAIL). Death receptor signaling represents part of an antiviral immune response in the infected host. The adenovirus E3 gene products also inhibit apoptosis induced by death receptor signaling, but this function is dispensable for productive virus replication in vitro (Wold et al. 
1999|. Viral DNA replication provides the switch to viral late-gene expression, the assembly and accumulation of virus particles in the nucleus (Shenk 2001), and eventual release of virus from the cell by a mechanism facilitated by expression of the adenovirus death protein (ADP; Tollefson et al. 1996). Rodent cells, which are semi- or nonpermissive for virus replication, are additionally susceptible to transformation by the adenovirus oncogenes $E 1 A$ and $E 1 B$, expressed from either plasmids or upon infection with adenovirus. Deregulation of cell growth control by E1A activates p53-dependent apoptosis that is directly inhibited by the E1B $55 \mathrm{~K}$ protein, and blocked downstream of p53 by vBCL-2, the E1B $19 \mathrm{~K}$ protein (Debbas and White 1993; Sabbatini et al. 1995; Henry et al. 2002). Thus, coordinate stimulation of cell cycle progression and disabling of apoptosis are required for both oncogenic transformation and productive infection. These apoptosis-related virus-host interactions also impact the use of adenovirus as a vector for human gene therapy (Vorburger and Hunt 2002), and as replicationbased anticancer agents (McCormick 2001). This increases the importance of establishing a detailed understanding of the interaction between adenovirus and its human host, in which apoptosis regulation plays a major role.

\section{Herpesviruses}

The Herpesviridae is a large family of DNA viruses (Kieff and Rickinson 2001; Roizman and Pellett 2001), representing more than 130 herpesviruses that are highly species-specific, with hosts that range from mammals and birds to amphibians and reptiles. There are three subfamilies of herpesviruses: $\alpha$, which includes herpes simplex virus (HSV) and varicella zoster virus (VZV); $\beta$, which includes cytomegalovirus (CMV); and $\gamma$, which includes human herpes virus 8 (HHV8) and Epstein-Barr virus (EBV). There are nine herpesviruses that have humans as the natural host, and these viruses are associated with significant disease. Herpesviruses productively replicate, and as with adenoviruses, viral DNA replication and virion assembly occur in the host nucleus. This leads to the ultimate destruction of the infected cell, but the infected host usually lives. Virus entry is followed by immediate early and early gene expression, viral DNA replication, partial late and late gene expression and synthesis of viral structural proteins, and virion assembly. The comparably large genome of herpesviruses (125-200 $\mathrm{kb}$ ) accommodates a substantial repertoire of genes involved in nucleic acid metabolism to create an ideal environment for virus replication, as well as still more gene products involved in disabling the antiviral defense system of the cell and host.

Herpesviruses also undergo latency and reactivation cycles, dictated by the environment of the host cell, that are far better understood mechanistically than those of adenoviruses (Kieff and Rickinson 2001; Roizman and Pellett 2001). Many herpesviruses have specific genes required for the establishment of latency, which occurs in the natural host and in specific cell types. In the latent state, the viral genome is present as a circular episome that replicates along with the DNA of the host cell, and there is no infectious virus produced. The latent state, however, does permit virus replication upon reactivation. Herpesviruses are also associated with the occurrence of some human cancers, which may represent an aberrant manifestation of the virus life cycle, particularly latency. The most notorious cancer-associated human herpesviruses are the $\gamma$-herpesviruses EBV and HHV8. EBV plays a major role in the development of Burkitt's lymphoma (BL), Hodgkin's Disease (HD), and nasopharyngeal carcinoma (Rickinson and Kieff 2001), and HHV8 is associated with the development of Kaposi's sarcoma and primary effusion lymphomas (Moore and Chang 2001). Tumorigenesis caused by herpesviruses, in general, appears to result from a combination of restricted expression of viral genes and genetic changes to the host cell, exemplified by c-myc translocation to the immunoglobulin heavy chain locus in cases of BL. The tumorigenic potential of herpesviruses is often enhanced in the immunocompromised, indicating an active role of the immune system in suppressing cancer development.

Unlike adenoviruses, herpesviruses have many hostacquired genes (Kieff and Rickinson 2001; Moore and Chang 2001; Roizman and Pellett 2001). The predominantly lymphotrophic $\gamma$-herpesviruses encode vBCL-2s, and as many as a dozen homologs of other cellular genes, and many of these genes have been modified compared with their cellular counterparts. The viral D-type cyclin (vCYCLIN), for example, does not respond to normal regulation by the cell, as may also be the case for the vBCL-2s. Although the well-known $\alpha$ - (HSV and VZV) and $\beta-(\mathrm{CMV})$ herpesviruses do not encode an obvious vBCL-2 homolog, they do encode other genes with antiapoptotic functions. Among the $\gamma$-herpesviruses that do encode vBCL-2s, there is substantial evidence that they function as apoptosis inhibitors in response to diverse stimuli. EBV BHRF1 blocks apoptosis induced by death receptor signaling (Kawanishi 1997), growth factor withdrawal (Henderson et al. 1993; Foghsgaard and Jäättelä 1997), granzyme B (Davis et al. 2000), $\gamma$ irradiation, chemotherapeutic drugs (McCarthy et al. 1996; Khanim et al. 1997), deregulated c-myc (Fanidi et al. 1998), and p53 (Tarodi et al. 1994; Theodorakis et al. 1996). A second EBV vBCL-2 homolog, BALF1, may either block apoptosis (Marshall et al. 1999) or antagonize BHRF1 (Bellows et al. 2002). HHV8 vBCL-2 inhibits apoptosis induced by BAX or vCYCLIN overexpression or Sindbis virus infection (Cheng et al. 1997b; Sarid et al. 1997; Ojala et al. 1999). Herpesvirus saimiri (HVS) vBCL-2 blocks FAS-, dexamethasone-, Sindbis virus-, and DNA damage-mediated apoptosis (Nava et al. 1997; Derfuss et al. 1998). Herpesvirus papio BHRF1 blocks apoptosis induced by DNA damage (Meseda et al. 2000), and murine $\gamma$-herpesvirus 68 (HV68) blocks apoptosis by anti-FAS antibody and TNF- $\alpha$ (Wang et al. 1999). A logical assumption is that the function of $\gamma$-herpesvirus vBCL-2s is necessary to protect the infected cell from apoptosis induction by 
either the immune system or by the infected cell itself. Perhaps vCYCLIN can stimulate cell cycle progression and apoptosis in a manner analogous to that of adenovirus E1A, thereby necessitating the need for expression of a vBCL-2.

EBV BHRF1 appears to be dispensable for lytic infection in vitro (Marchini et al. 1991; Lee and Yates 1992), but given the repertoire of other antiapoptotic genes encoded by EBV, particularly the gene encoding latent membrane protein 1 ( $\operatorname{lmp} 1$; Kieff and Rickinson 2001), this is not surprising. Until recently, it has not been clear what the physiological role of vBCL-2 was in the life cycle of herpesvirus, which was in part owing to the lack of a good animal model for herpesvirus infection that faithfully represented productive acute, latent, and reemergent infection. The EBV- and HHV8-related murine $\gamma$-herpesvirus HV68, and the corresponding mutant viruses that lack v-cyclin and $v b c l-2$, have enabled some of these issues to be addressed.

\section{Poxviruses}

The Poxviridae are large, structurally complex viruses with DNA genomes that comprise some of the most dreaded human and animal pathogens yet discovered. Poxviruses are composed of two groups that infect either vertebrates (Chordopoxvirinae) or arthropods (Entimopoxvirinae; Moss 2001). In the life cycle of vaccinia, considered as the prototypical poxvirus, entry and uncoating are followed by immediate transcription of viral genes by a set of transcription factors that is contained within the virion particle itself. Replication of the viral DNA through the activity of a virus-encoded DNA polymerase occurs in the cytoplasm, a feature that is shared by African swine fever virus (ASFV). In the later stages of infection, expression of structural proteins culminates in the assembly and release of daughter virion particles (Moss 2001). The large genome of poxviruses (130-300 kb) encodes numerous nonBCL-2 apoptosis inhibitors such as the caspase inhibitory serpins or viral FLICE inhibitory proteins (vFLIPs), as well as soluble TNF receptors (Barry and McFadden 1998; Roulston et al. 1999|, which may obviate the need to encode a vBCL-2. Despite the large repertoire of antiapoptotic and immune stealthing functions encoded by poxviruses, vBCL-2s are encoded by FPV and the poxvirus-like ASFV. The role that apoptosis plays in the pathology and the life cycle of poxviruses is not well understood, but it almost certainly functions as a factor in limiting viral replication, given the extensive array of antiapoptotic functions encoded by this virus family. As such, antiviral therapies that stimulate apoptosis of the infected cell may prove useful in controlling poxvirus infections.

It is unclear exactly how infection by poxviruses induces apoptosis, but it may be a generalized response to subversion of host-cell metabolism such as the shutoff of host macromolecule synthesis that occurs during viral infection. Fowlpox (FPV) is capable of inducing hyperpla- sia in infected tissues (Cheevers et al. 1968), and this effect may represent a loss of cell cycle control to which the cell responds with a death signal. FPV is a member of the genus Avipoxvirus, and is the only poxvirus known to encode a BCL-2 homolog (FPV039), which closely resembles the prosurvival BCL-2 family member MCL-1 (Afonso et al. 2000). It is possible that other members of the same genus will also turn out to encode vBCL-2s.

ASFV is a large enveloped DNA virus encoding 151 predicted genes. Although it is the only representative of the new family Asfarviridae, ASFV shares some characteristics with the poxviruses, namely, the structure of its genome and cytoplasmic localization of its replication complexes. African swine fever is an economically important, often fatal illness of domestic pigs that is transmitted by ticks. The affected tissues are destroyed by apoptosis (Gomez-Villamandos et al. 1995; Ramiro-Ibanez et al. 1996; Oura et al. 1998), and the degree of cell death induction correlates with the lethality of the infecting strain. However, the tissues displaying the highest proportion of apoptotic cells also have the lowest rates of viral replication (Oura et al. 1998), a phenomenon that complements the observation that ASFV-induced apoptosis requires only adsorption and uncoating, and not viral replication (Carracosa et al. 2002). Although the pathology of ASFV disease is typified by the massive induction of apoptosis, the virus also expresses apoptotic inhibitors. Therefore, how or why cell death occurs is unclear, but it may be a result of "bystander" apoptosis induced in uninfected tissues (Oura et al. 1998).

ASFV encodes numerous cell-acquired genes, including the BCL-2 homolog A179L in the BA71V strain (originally termed LMW5-HL in the Malawi strain; Neilan et al. 1993; Yanez et al. 1995). When exogenously expressed, A179L can protect cells from apoptosis induced by IL-3 withdrawal (Afonso et al. 1996), the interferoninduced p68 kinase (PKR; Brun et al. 1996), and the inhibition of macromolecular synthesis (Revilla et al. 1997). Interestingly, A179L can also repress baculovirusinduced apoptosis in Sf9 insect cells (Brun et al. 1998), indicating a very low degree of species-specificity, as would be required of a viral protein that probably must function in both a mammal and an arthropod. The role of the ASFV vBCL-2 in the virus life cycle and its mechanism of action remain to be determined.

\section{Functional and structural organization of the BCL-2 family}

The cBCL-2 family encodes more than a dozen mammalian members in addition to homologs in Caenorhabditis elegans and Drosophila melanogaster (Gross et al. 1999a). Family members are highly conserved throughout evolution, most notably in highly conserved BCL-2 homology regions (BH) 1-4. Three different subgroups of BCL-2-related proteins have been identified: those that promote survival such as BCL-2 and BCL- $\mathrm{x}_{\mathrm{L}}$, which en- 
code $\mathrm{BH} 1-\mathrm{BH} 4$; those that promote cell death such as $\mathrm{BAX}$ and $\mathrm{BAK}$, which encode $\mathrm{BH} 1-\mathrm{BH} 3$; and those that promote cell death such as BID, NBK/BIK, and BAD, which encode only $\mathrm{BH} 3$ (BH3-only proteins). $\mathrm{BH} 3$ is a binding domain used for homo- and heterodimerization between BCL-2 family members. A large region in the center of the BCL-2 proteins encompassing BH1-BH3 forms a hydrophobic pocket that serves as the receptor for $\mathrm{BH} 3$. BH4, which is only present within the antiapoptotic family members, is thought to be a regulatory domain. Most family members also possess a putative membrane-targeting transmembrane region (TM) at the C terminus.

BCL-2 family members function by interacting with each other, and by either promoting or antagonizing the function of the binding partner (Gross et al. 1999a). These protein-protein interactions rely on the $\mathrm{BH} 3$ of one protein interacting with the hydrophobic cleft created by BH1-BH3 of the other (Sattler et al. 1997). The $\mathrm{BH}$-only protein $\mathrm{BAD}$, for example, can interact with $B C L-x_{L}$ to antagonize its survival function. Alternatively, the BH3-only protein BID can be cleaved by caspase-8 during death receptor-mediated apoptosis to truncated BID (tBID), which reveals its $\mathrm{BH} 3$ and allows interaction with BAX and BAK to promote their proapoptotic function (Gross et al. 1999a). In turn, BCL-2 and BCL- $\mathrm{x}_{\mathrm{L}}$ interact with BID and tBID to prevent BAX and BAK activation, blocking apoptotic signaling. BCL-2 and BCL- $\mathrm{x}_{\mathrm{L}}$ can also bind BAX and BAK, and block apoptosis. However, the preferred targets of BCL-2 and BCL- $\mathrm{x}_{\mathrm{L}}$ may depend on differential $\mathrm{BH} 3$-binding affinity and the physiological context.

BH3-only proteins are upstream regulators of BAX and BAK that promote apoptosis by facilitating the release of mitochondrial proteins such as holo-cytochrome $c$ and SMAC/DIABLO from the intermembrane space /Cheng et al. 2001; Wei et al. 2001; Zong et al. 2001; Degenhardt et al. 2002). Cytochrome $c$ is a cofactor for APAF-1-dependent caspase-9 activation in the apoptosome complex, whereas SMAC/DIABLO is an antagonist of the inhibitor of apoptosis proteins (IAPs) that act as direct negative regulators of caspase activation (Wang 2001; Shi 2002). Apparently, many death signaling pathways rely on $\mathrm{BH} 3$-only proteins activating BAX and BAK to propagate caspase activation and apoptosis through mitochondria, as cells deficient for both BAX and BAK are resistant to apoptosis mediated by $\mathrm{BH} 3$-only proteins and their upstream stimuli (Lindsten et al. 2000; Cheng et al. 2001; Wei et al. 2001; Zong et al. 2001; Degenhardt et al. 2002). Without BAX and BAK, the release of cytochrome $c$, SMAC/DIABLO, and perhaps other proapoptotic mitochondrial proteins is severely impaired, illustrating the functional requirement for BAX and BAK for this activity. Interestingly, cells singly deficient in either BAX or BAK are capable of releasing cytochrome $c$, activating caspase-9, and undergoing apoptosis, indicating that BAX and BAK are functionally redundant. Thus, abrogation of apoptotic signaling may require inhibition of the upstream $\mathrm{BH} 3$-only protein or inactivation of both BAX and BAK.

\section{Interaction with and inhibition of proapoptotic BAX and BAK by vBCL-2s}

The first indication that the adenovirus vBCL-2 E1B 19K protein functioned biochemically by similar mechanisms to cBCL-2s emerged when yeast two-hybrid screening using E1B $19 \mathrm{~K}$ as bait identified BAX and BAK as interacting proteins (Farrow et al. 1995; Han et al. 1996a). BAX was originally cloned as a protein that coimmunoprecipitated from mammalian cells with BCL-2 (Oltvai et al. 1993), and BAK was isolated from two-hybrid screens using BCL-2 as bait (Chittenden et al. 1995; Kiefer et al. 1995). E1B 19K inhibited BAX- and BAKmediated apoptosis similarly to BCL-2, and it did so by interacting with the BH3 of BAX (Han et al. 1996a), and probably also that of BAK. In the case of BAX-mediated apoptosis, BAX BH3 was both necessary and sufficient for E1B 19K interaction, and E1B 19K BH1 mutants that lose BAX-binding activity no longer block apoptosis (Han et al. 1996a; Han et al. 1998a). In an analogous manner, BH1 mutations in ASFV vBCL-2 (A179L), or $\mathrm{BH} 1$ and $\mathrm{BH} 2$ mutations in EBV BHRF1, also eliminate their antiapoptotic activity (Khanim et al. 1997; Revilla et al. 1997). This suggests that E1B 19K, and perhaps other vBCL-2s, act as receptors for BH3s of proapoptotic $\mathrm{BAX}$ and $\mathrm{BAK}$, and antagonize their function.

Activation of the proapoptotic function of BAX and BAK requires interaction with $\mathrm{BH} 3$-only proteins and a series of changes in BAX and BAK conformation, and the E1B 19K-BAX and E1B 19K-BAK interactions were informative in establishing the order of events during the activation process. E1B 19K-BAX interaction requires a change in BAX conformation provided, for example, by hit-and-run binding of tBID to BAX, presumably to expose BAX BH3. Thus the E1B $19 \mathrm{~K}$ protein is not normally found bound to BAX in healthy cells in the absence of a death stimulus (Perez and White 2000; Sundararajan and White 2001; Sundararajan et al. 2001; Cuconati et al. 2002). This requirement for altered protein conformation to reveal binding activity of proapoptotic proteins may explain some conflicting reports on vBCL-2-BAX and vBCL-2-BAK binding activity. HHV8 vBCL-2 does not bind in vitro translated BAX and BAK (Cheng et al. 1997b), but the purified vBCL-2 protein does bind $\mathrm{BAX}$ and $\mathrm{BAK} \mathrm{BH} 3$ peptides with high affinity (Huang et al. 2002). EBV BALF1 associates with BAX and BAK (Marshall et al. 1999), or rather may antagonize BHRF1 (Bellows et al. 2002). Indeed, other vBCL-2s may interact with and inhibit BAX and BAK. EBV BHRF1 binds BAK, BCL-2, BCL- $\mathrm{x}_{\mathrm{L}}$, and BCL- $\mathrm{x}_{\mathrm{S}}$, but not BAX (Theodorakis et al. 1996); and HVS vBCL-2 binds BAX and BAK (Nava et al. 1997). Because vBCL-2 proteins may interact with cellular apoptotic regulators in a conformation-dependent fashion, it may be essential to examine their function and binding abilities in vivo and in the presence of a physiologically relevant death stimulus. Furthermore, as conformational changes in BAX and BAK as well as dimerization of BCL-2 family members are artifactually induced by detergents commonly used for immunoprecipitation (Hsu and Youle 1997, 1998), it 
is important to examine BCL-2 family protein interactions in the absence of these detergents.

\section{vBCL-2s may prefer BAX and BAK as targets over BH3-only proteins}

Two-hybrid screening with the E1B 19K protein as bait identified the first proapoptotic $\mathrm{BH} 3$-only protein NBK/ BIK as well as BNIP3 (Boyd et al. 1994, 1995; Han et al. 1996b), revealing that BAX and BAK were not necessarily the only vBCL-2 targets. Although E1B 19K interacts with and inhibits apoptosis induced by NBK/BIK and BNIP3 overexpression, the physiological context of these activities still remains to be determined. Although BCL-2 also interacts with NBK/BIK, E1B 19K does not interact with the BCL-2 and $\mathrm{BCL}-\mathrm{x}_{\mathrm{L}}$ interacting $\mathrm{BH} 3$ only proteins BAD, BID, and tBID /Chen et al. 1996; Perez and White 2000). Thus, there are distinct binding specificities that distinguish E1B 19K, and possibly other vBCL-2s, from cBCL-2s. Perhaps vBCL-2s would prefer to target for inhibition the core apoptotic machinery, represented by $\mathrm{BAX}$ and $\mathrm{BAK}$, rather than the upstream regulators represented by the $\mathrm{BH} 3$-only proteins. A possible preference of vBCL-2s for BAX and BAK over BH3only proteins may be a matter of efficiency, as BH3-only proteins may vary in their regulation and expression in different cell types. This may make them more elusive, and thereby less desirable targets for vBCL-2s.

\section{Sequence and structural similarities between vBCL-2 and $\mathrm{CBCL}-2$ proteins}

vBCL-2 proteins predominantly act as apoptosis inhibitors in cases in which their function has been examined, and they encode most of the recognizable $\mathrm{BH}$ regions (Figs. 1, 2). Thus, vBCL-2s are expected to be somewhat similar in structure to cBCL-2s. $\mathrm{BH} 3$ and $\mathrm{BH} 4$ are least conserved at the level of sequence identity among vBCL$2 s$, and between vBCL-2s and cBCL-2s, but the structure in these regions may nonetheless be conserved (see below). Many, but not all, vBCL-2s also possess a predicted C-terminal TM region (Figs. 1, 2). The adenovirus E1B $19 \mathrm{~K}$ protein does not possess a TM, and may be membrane-associated by virtue of posttranslational fatty acid acylation (McGlade et al. 1987). All vBCL-2s have a recognizable $\mathrm{BH} 1$ and at least one other $\mathrm{BH} 2$ or $\mathrm{BH} 3$, likely preserving the sequence of the highly conserved central part of the proteins, which can serve as a receptor for $\mathrm{BH} 3 . \mathrm{BAX} \mathrm{BH} 3$ is sufficient for interaction with the central highly conserved region of E1B $19 \mathrm{~K}$ that encompasses $\mathrm{BH} 3$ and $\mathrm{BH} 1$; therefore, the absence of a recognizable $\mathrm{BH} 2$ still enables formation of the presumptive BH3-binding site (Han et al. 1996a, 1998a).

With the determination of the crystal structure of BCL- $\mathrm{x}_{\mathrm{L}}$ minus the TM, it emerged that BCL-2 family members bore a striking similarity to the pore-forming domains of bacterial toxins (Muchmore et al. 1996; Aritomi et al. 1997). BCL- $\mathrm{x}_{\mathrm{L}}$ possesses two central helices surrounded by amphipathic helices interconnected sometimes by large unstructured loops. The structure of BCL-2 is highly similar to that of BCL- $\mathrm{x}_{\mathrm{L}}$ (Petros et al. 2001), and, surprisingly, so is that of the BH3-only protein BID (Chou et al. 1999; McDonnell et al. 1999). Thus structural homology is conserved between BID and BCL$\mathrm{x}_{\mathrm{L}}$ even in the absence of obvious sequence homology outside of BH3. BID cleavage to tBID is predicted to reveal its $\mathrm{BH} 3$ and thereby the proapoptotic activity of tBID. The arrangement of the helices in BCL- $x_{L}$ and BCL-2 creates a hydrophobic cleft on the surface of the proteins that serves as a binding pocket for $\mathrm{BH} 3$ regions (Sattler et al. 1997). The solution structure of BAX with its transmembrane region intact revealed that the TM resided within the hydrophobic cleft reserved for $\mathrm{BH} 3$ (Suzuki et al. 2000). This suggested that homo- and heterodimerization between BCL-2 family members requires a change in protein conformation whereby the TM would be displaced from the BH3-binding pocket to allow protein interactions to take place. These protein interactions could occur by $\mathrm{BH} 3$ or TM binding of one BCL-2 family member to the pocket of another. Because the TM of BAX resides in the $\mathrm{BH} 1-\mathrm{BH} 3$-binding pocket for $\mathrm{BH} 3$ and presumably occludes binding to the pocket (Suzuki et al. 2000), the absence of TM in E1B 19K raises the possibility that its $\mathrm{BH} 3$-binding pocket is constitutively exposed. If so, then the E1B $19 \mathrm{~K}$ protein, and perhaps other vBCL-2s that lack a TM, may be active scavengers of exposed $\mathrm{BH} 3 \mathrm{~s}$. The overall theme of changes in protein conformation to control binding and function is reminiscent of how the pore-forming domains of bacterial toxins work, and this method may have been usurped by cBCL-2s and exploited by vBCL- 2 .

When activated, the pore-forming domains of bacterial toxins undergo a change in conformation that exposes the two central helices, which are then thought to insert into the bacterial membrane and oligomerize to form a pore to release bacterial contents (Gazit et al. 1998; Gilbert et al. 1999; Manoj and Aronson 1999; Gerber and Shai 2000; Wallace et al. 2000). The structural homology of BCL-2 family members with the domains of bacterial toxins suggests the possibility of a related biochemical activity. Although it is still controversial how BCL-2 family members function at the biochemical level, there are distinct parallels between the function of BAX and BAK and that of the toxin pore-forming domains.

The solution structure of the first vBCL-2, that of HHV8 vBCL-2, has recently been determined. The overall fold is highly similar to that of the cBCL-2s, with the exception that the unstructured loop regions interconnecting the helices are smaller (Huang et al. 2002). The vBCL-2s are uniformly smaller proteins than their cellular counterparts, and the preservation of the overall fold at the expense of the unstructured loops may have allowed that to occur (Figs. 1, 2). In cBCL-2s the loops encode sites for phosphorylation and proteolysis, which may be required for regulating the function of these proteins in development and maintaining homeostasis (Haldar et al. 1995; Uhlmann et al. 1996; Chang et al. 1997; Cheng et al. 1997a; Bellows et al. 2000). These regulatory events, which are uniformly inhibitory to antiapoptotic 
Function of vBCL-2s

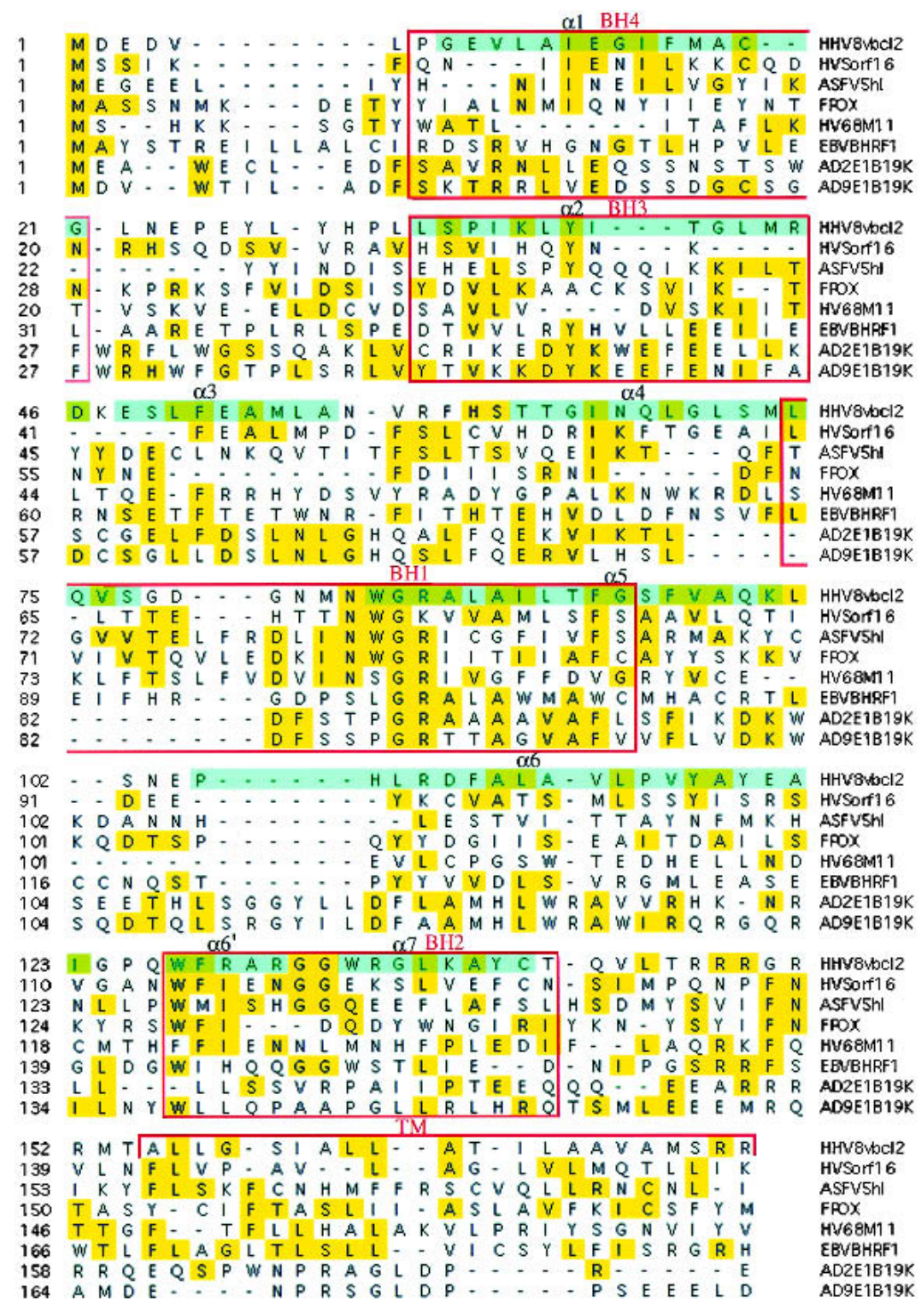

Figure 1. Sequence and structural homology among vBCL-2s. Multiple sequence alignment among vBCL-2 proteins encoded by adenoviruses, herpesviruses, and poxviruses. The coding regions for the vBCL-2 genes were subjected to multiple sequence alignment (Megalign, DNA ${ }^{*}$, Clustal Method). Regions with conserved, identical amino acids are shaded in yellow. The green overlay indicates the location of $\alpha$-helices from the solution structure of HHV8 vBCL-2 (Huang et al. 2002). The locations of the BCL-2 homology (BH) and transmembrane (TM) regions are indicated in red. GenBank accession numbers for the protein sequences used are listed below in parentheses. (HHV8vbcl-2) Human herpesvirus 8 vBCL-2 (NP-572068); (HVSorf16) herpesvirus saimiri orf16 vBCL-2 (NP-040218); (ASFV5HL) African swine fever virus A179L/LMW-5HL vBCL-2 (Q07818); (FPOX) fowlpox virus 039 vBCL-2 (NP-039002); (HV68M11) herpesvirus 68 M11 vBCL-2 (NP-044912); (EBVBHRF1) Epstein-Barr virus BHRF1 vBCL-2 (P03182); (AD2E1B19K) adenovirus type 2 E1B 19K vBCL-2 (NP-040510); (AD9E1B19K) adenovirus type 9 E1B 19K vBCL-2 (AAD16304).

family members, would be expected to be detrimental to the viral counterparts, which may account for the absence of conservation of the loops. In contrast to cBCL$2 \mathrm{~s}, \mathrm{E} 1 \mathrm{~B} 19 \mathrm{~K}$ is not functionally altered by phosphorylation (McGlade et al. 1989), and vBCl-2s are not cleaved (Bellows et al. 2000). Structural similarity is preserved, however, even with limited conservation of amino acid sequence. For example, $\mathrm{BH} 4 / \alpha 1$ and $\mathrm{BH} 3 / \alpha 2$, which are poorly conserved in HHV8, correspond to $\alpha 1$ and $\alpha 2$, and BH4 and BH3 of BCL- $x_{\mathrm{L}}$ and BCL-2 (Huang et al. 2002). Whether the poor conservation of primary sequence in these regions in other vBCL-2s still permits conservation of protein structure, or represents distinct differences in structure and function, remains to be determined.

The hydrophobic BH3-binding cleft is conserved in HHV8 vBCL-2, and it binds with high affinity to peptides encoding $\mathrm{BH} 3$ derived from $\mathrm{BAK}$ and $\mathrm{BAX}$, and, to a much lesser extent, BAD (Huang et al. 2002). This was somewhat surprising because HHV8 vBCL-2 was originally thought not to bind BAK and BAX /Cheng et al. 1997b). A BH3-only protein-dependent change in conformation of BAX and BAK that dislodges TM and reveals 
$\mathrm{Bcl}-2$

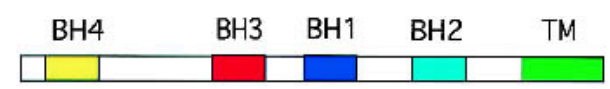

HHV8 vBCL-2

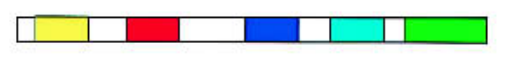

HVS orf 16

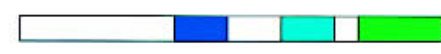

ASFV A179L

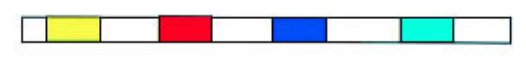

FPV 039

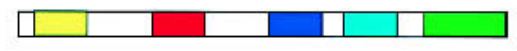

HV68 M11

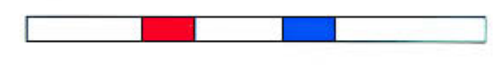

EBV BHRF 1

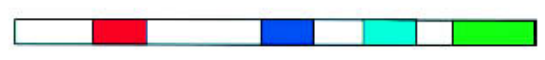

AD E1B 19K

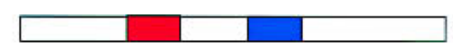

Figure 2. Conservation of $\mathrm{BH}$ and TM regions among vBCL-2s. BCL-2 homology regions and their conservation among viral homologs. Predicted domain organization of vBCL-2 proteins. Indicated is the probable presence of the BCL-2 homology (BH) and transmembrane (TM) regions based on sequence homology (Fig. 1). Note that low homology, particularly in $\mathrm{BH} 4, \mathrm{BH} 3$, and $\mathrm{BH} 2$, suggests the absence of these regions in some vBCL-2s, which could nonetheless be conserved at the level of protein structure. (HHV8 vBCL-2) Human herpesvirus 8 vBCL-2; (HVS orf16) herpesvirus saimiri open reading frame 16 vBCL-2; (ASFV A179L) African swine fever virus A179L/LMW-5HL vBCL-2; (FPV 039) fowlpox virus 039 vBCL-2; (HV68 M11) herpesvirus 68 M11 vBCL-2; (EBV BHRF1) Epstein-Barr virus BHRF1 vBCL2; (AD2E1B19K) adenovirus type 2 E1B 19K vBCL-2.

$\mathrm{BH} 3$ and the hydrophobic cleft, may be required for HHV8 vBCL-2 binding potential. This may necessitate that BAX and BAK binding activity be assessed in vivo in the presence of a physiological death stimulus. Taken together, these observations suggest that vBCL-2 proteins may target BAX and BAK, and may not be subject to the regulatory mechanisms that control the function of, particularly inactivate, cBCL-2s.

\section{BAX and BAK function as antiviral response to abort virus replication and persistent infection}

In adenovirus-infected cells, the expression of E1A causes the inappropriate entry of the cell into an S-phaselike state, which facilitates replication of the viral genomic DNA (White 1994, 2001). The resultant onset of apoptosis is thought to compromise the viability of the infected cell, and possibly abort the viral replication cycle. To counteract this effect, expression of E1B 19K functions to block apoptosis induced by cell cycle deregulation. Deletion or mutation of the $E 1 B 19 \mathrm{~K}$ gene confers the cyt and deg viral phenotypes, in which the infected cell's genomic DNA as well as replicated viral DNA are degraded (Pilder et al. 1984; Subramanian et al. 1984; Takemori et al. 1984; White et al. 1984). The E1B $19 \mathrm{~K}$ viral mutants usually replicate to lower levels than the wild-type virus, presumably because of apoptotic destruction of the infected cell. The replication of E1B 19K mutants can be rescued by the inhibition of apoptosis in the infected cell (Chiou and White 1998; Cuconati et al. 2002). These observations support the concept of apoptosis as a limiting factor in the life cycle of DNA viruses, to which some viruses respond with the expression of antiapoptotic homologs of BCL-2.

The antiapoptotic function of E1B $19 \mathrm{~K}$ can mostly be attributed to its ability to bind to BAX and BAK. In productively infected cells, E1A expression correlates with a conformational change in BAK in which the $\mathrm{N}$ terminus is exposed (Cuconati et al. 2002). In cells infected with E1B $19 \mathrm{~K}$ viral deletion mutants, the altered form of BAK forms a complex with BAX. This BAK-BAX interaction may be a key event, because it is followed by stepwise conformational changes in BAX that likely result in exposure of the $\mathrm{BH} 3$, mirroring the effects of tBID interaction with BAX. BAK and BAX form high-molecularweight complexes in apoptotic cells (Antonsson et al. 2000; Eskes et al. 2000; Korsmeyer et al. 2000; Sundararajan and White 2001; Sundararajan et al. 2001). These BAX and BAK complexes are associated with the release of cytochrome $c$ and SMAC/DIABLO from the intermembrane space of mitochondria into the cytosol, resulting in the cytochrome $c$-dependent activation of the APAF1/caspase-9 complex, and presumably SMAC/ DIABLO-dependent inhibition of IAPs, which may facilitate activation of caspase-3. In adenovirus-infected cells, E1B $19 \mathrm{~K}$ binds BAK and abrogates the interaction of BAK and BAX, which prevents the conformational changes that activate BAX and the release of cytochrome $c(\mathrm{Cu}-$ conati et al. 2002). Therefore, the mechanism by which E1B 19K blocks apoptosis to allow the progress of productive infection centers on a block of the mitochondrial checkpoint caused by inhibition of BAK and BAX.

Although E1B 19K may possess functions independent of influencing BAX/BAK interactions (Rao et al. 1997; Han et al. 1998b; Kasof et al. 1998; Perez and White 1998), studies of adenovirus infection of cells deficient for BAX and BAK demonstrated that this is a major aspect of E1B $19 \mathrm{~K}$ activity in apoptosis regulation. The dependence of adenovirus-induced apoptosis on BAK and BAX is demonstrated by the observation that in semipermissive mouse cells deficient for BAX and BAK, the growth disadvantage that is conferred by an E1B $19 \mathrm{~K}$ deletion is abolished (Cuconati et al. 2002). Therefore, the loss of a vBCL- 2 can be complemented by the absence of BAK and BAX. Given the striking difference in viral replication in the BAX- and BAK-deficient semipermissive mouse cells, it will be of interest to examine the replication capacity of adenoviruses in permissive human cells deficient for BAX and BAK.

If cells deficient for BAK and BAX are infected with adenovirus, the onset of cytopathic effects is delayed, and the absence of BAK and BAX allows more efficient viral replication than that which occurs in infection of wild-type cells. This may be responsible for the propensity of these cells to allow long-term persistent infection to occur in culture (A. Cuconati and E. White, in prep.). 
BCL-2 overexpression facilitates persistent infection by human immunodeficiency virus (HIV) and Sindbis virus (Levine et al. 1993; Antoni et al. 1995), indicating that the course of virus infection can be altered by either the gain of a survival activity or the loss of an apoptotic activity. Persistent infection by adenovirus has been observed repeatedly both in vitro and in clinical cases. Primary cultures of human monocytes, continuous B-cell lines, and isolated lymphoid tissues have been documented as sustaining long-term adenoviral infections (Van Der Veen and Lambriex 1973; Chu et al. 1992; Flomenberg et al. 1996). The variables that may determine whether persistent infection occurs may relate to a particular genotype of the infecting viral strain, the expression levels of proapoptotic factors in the affected tissues, or to the insensitivity of those tissues to E1A expression. It is unknown whether the establishment of persistent infection in those cases depends on an inability of the infected tissues to initiate an apoptotic response, but it arises as an intriguing possibility. In experimental or clinical situations in which persistent infection is observed, analysis of the apoptotic status of the infected cell type may well reveal that such cells are not responding with the cell death signaling cascade, suggesting that therapies meant to stimulate the progress of cell death may aid in the management of persistent adenovirus infections in the clinic.

\section{vBCL-2s enable emergence from latency and establishment of chronic, persistent infection}

As the coordination between deregulation of cell cycle control and inhibition of apoptosis by E1A and E1B 19K is critical for productive replication and persistent infection in vitro by adenoviruses, these same activities appear to be important for reemergence from latency and persistent infection in vivo by $\gamma$-herpesviruses. The acute, latent, reemergent, and chronic phases of infection of the murine herpesvirus HV68, which encodes a D-type vCYCLIN and a vBCL-2 (Virgin et al. 1997), have been examined in vivo. HV68 viral stop-codon and frame-shift mutants that lack either the v-cyclin or $V$ $b c l-2$ display no prominent defects in acute replication in vitro or in vivo in wild-type or immunocompromised mice (Hoge et al. 2000; Van Dyk et al. 2000; Gangappa et al. 2002). EBV BHRF1 is also dispensable for acute virus replication (Marchini et al. 1991; Lee and Yates 1992). Establishment of HV68 viral latency was also unaffected by v-cyclin or $v$-bcl-2 mutations (Hoge et al. 2000; Van Dyk et al. 2000; Gangappa et al. 2002). It is probably not surprising that vBCL-2 function is not required during acute replication and establishment of latency, given that herpesviruses encode multiple gene products that are probably functionally redundant inhibitors of apoptosis, including LMP1 and vFLIP. Alternatively, modulation of the cell cycle and apoptosis by the virus may be unnecessary for these aspects of the virus life cycle.

In contrast to their dispensability in acute and latent infection, both the HHV8 v-cyclin and $v$-bcl-2 are required for efficient reemergence from latency, persistent infection, and pathogenesis. HV68 v-cyclin or $v$-bcl-2 mutant viruses display significant defects in reemergence from latency as measured by spontaneous ex vivo reactivation, and in persistent replication and virulence (Hoge et al. 2000; Van Dyk et al. 2000; Gangappa et al. 2002). Because latently infected cells are not cycling, it is possible that $\mathrm{v}$-cyclin expression may be required to stimulate cell cycle progression; however, it may also induce apoptosis, thereby necessitating the presence of an antiapoptotic vBCL-2. Indeed, HV68 or HHV8 vCYCLIN overexpression stimulates cellular DNA synthesis and apoptosis (Ojala et al. 1999; Van Dyk et al. 1999), as does adenovirus E1A (White 1994, 2001). Direct assessment of apoptosis induction by vCYCLIN expression in a $v$-bcl-2 mutant but not in wild-type infected cells during reemergence from latency would be informative, but may be technically challenging. Furthermore, if apoptotic signaling by vCYCLIN requires BAX and/or BAK, and there are indications that herpesvirus vBCL-2s may interact with and inhibit BAX and BAK, it will be of interest to evaluate the herpesvirus life cycle in cells or animals deficient for BAX and/or BAK expression. A prediction is that BAX and BAK deficiency should rescue defective reemergence from latency, persistent infection, and pathogenesis of a $\mathrm{v}$-bcl-2 mutant herpesvirus. Given that these are aspects of the herpesvirus life cycle that are associated with human disease, they present an opportunity for therapeutic intervention.

\section{Inhibition of death receptor signaling by vBCL-2 proteins}

Immune surveillance by the host organism would partially entail attacking the infected cell with secreted TNF- $\alpha$, FasL, or TRAIL. One possible function of the vBCL-2 proteins, therefore, would be to prevent death of the infected cell due to signaling by death cytokines. There are several examples of inhibition of death receptor signaling by $\mathrm{vBCL}-2$ proteins. The BHRF1 protein of EBV is capable of inhibiting both TNF- $\alpha$ - and FasL-induced death, but its activity may be cell-type-specific (Foghsgaard and Jäättelä 1997; Kawanishi 1997). BALF1, also encoded by EBV, is capable of blocking FAS-mediated death signaling in cells sensitized by IFN $\gamma$ (Marshall et al. 1999). The M11 protein of HV68 can inhibit TNF- $\alpha$ and FasL-induced death (Wang et al. 1999), and the vBCL-2 of HVS blocks FAS signaling in a cell-typedependent manner (Derfuss et al. 1998). The presence of redundant antiapoptotic functions in many viral genomes makes it unclear what the overall contribution of vBCl-2 proteins is to inhibition of cytokine death signaling during infection. It remains possible that inhibition of apoptosis mediated by death receptors by vBCL-2s is an indirect consequence of inhibition of the core apoptotic machinery represented by BAX and BAK, which may block yet another apoptotic pathway. Alternatively, it may be so critically important to block apoptosis by death receptor ligands that viruses encode redundant inhibitory mechanisms to ensure survival of the infected cell. 
The system in which inhibition of death receptor-mediated apoptosis by vBCL-2s has been explored most thoroughly is with adenoviruses. In human cells, expression of the adenovirus type 2 or 5 E1B $19 \mathrm{~K}$ potently inhibits apoptosis induced by TNF- $\alpha$, anti-FAS antibodies, and TRAIL (Gooding et al. 1991; Hashimoto et al. 1991; White et al. 1992; Tollefson et al. 2001). Because E1B 19K does not appear to affect recruitment and assembly of the death-inducing signaling complex (DISC; Perez and White 1998), nor does it alter death receptor signaling events upstream of mitochondria (Perez and White 2000), its activity is probably caused by its interactions with BAX and BAK. TNF- $\alpha$ or FasL death signaling through the mitochondria is dependent on the production of tBID by the cleavage of the $\mathrm{N}$ terminus of BID by activated caspase-8 (Li et al. 1998; Gross et al. 1999b). Localization of tBID to the mitochondria and its subsequent interaction with BAX and BAK induce conformational changes in BAX and BAK that expose their $\mathrm{N}$ and C termini (Perez and White 2000; Sundararajan and White 2001). BAX and BAK then oligomerize (Sundararajan and White 2001), to form a high-molecular-weight complex (Eskes et al. 2000; Korsmeyer et al. 2000; Wei et al. 2000; Sundararajan and White 2001; Sundararajan et al. 2001). Interaction of BAX with E1B $19 \mathrm{~K}$ is dependent on the tBID-induced conformational change in the BAX $\mathrm{N}$ terminus (Perez and White 2000), and E1B 19K prevents BAX-BAK complex formation and oligomerization (Sundararajan and White 2001; Sundararajan et al. 2001). BAK also interacts with E1B $19 \mathrm{~K}$ in TNF- $\alpha$-treated cells, but the conformational status of BAK is irrelevant to the interaction (Sundararajan et al. 2001). E1B 19K expression blocks the release of both cytochrome $c$ and SMAC/ DIABLO from mitochondria, prevents the activation of caspase-9, and interrupts the proteolytic processing and activation of the caspase- 3 p20 subunit to remove the prodomain (Perez and White 2000). Whereas TNF- $\alpha$-dependent caspase- 8 activation and cleavage of caspase- 3 by caspase- 8 to liberate the C-terminal p12 subunit of caspase-3 occurs normally in E1B 19K-expressing cells (Perez and White 2000), the failure to release SMAC/ DIABLO from mitochondria may prevent the completion of caspase-3 activation. SMAC/DIABLO is likely required to relieve the inhibitory effects of IAPs on p20 caspase-3; thus, SMAC/DIABLO mimetics may be useful for overcoming vBCL-2 inhibition of death receptor signaling. E1B 19K appears to prevent death receptormediated apoptosis by blocking the tBID-induced release of proapoptotic mitochondrial proteins through direct inhibition of BAX and BAK function. This contrasts with the activity of BCL-2 and BCL- $\mathrm{x}_{\mathrm{L}}$, which work at least partially by binding to BID and tBID (Li et al. 1998; Luo et al. 1998). Thus, E1B 19K may be a more generalized apoptosis inhibitor than its cellular homologs, working at the key downstream checkpoint in order to prevent death from a wider variety of stimuli. Depending on what those upstream death stimuli are, E1B 19K can inhibit BAX, BAK, or both BAX and BAK.

The abrogation of death receptor signaling would ostensibly allow the infected cell to escape immune sur- veillance by rendering it resistant to the actions of TNF$\alpha$, FasL, and TRAIL. Again, as with most other DNA viruses, the activity of E1B 19K during adenovirus infection is only part of a multilayered response to apoptosis induction; however, studies with E1B $19 \mathrm{~K}$ mutants do demonstrate that the adenovirus BCL-2 homolog is instrumental to the survival of the infected cell in the face of death receptor signaling.

\section{Role of vBCL-2s in oncogenesis}

Viruses, particularly herpesviruses, are significant etiological agents in human cancer (Moore and Chang 2001; Rickinson and Kieff 2001). Viral oncogenesis can result from a combination of viral gene expression, changes in host-cell gene expression, and impairment of immune function. Adenoviruses, although not known to be a factor in human cancer, are oncogenic in rodents, and it is the viral genes involved in deregulating control of cell proliferation $(E 1 A)$ and inhibiting apoptosis $(E 1 B)$ that are essential for this process. vBCL-2 expression inhibits apoptosis induced by the p53 tumor suppressor protein (Tarodi et al. 1994; Sabbatini et al. 1995), as does BCL-2 (Chiou et al. 1994a), the deregulation of which is associated with human follicular lymphoma. Herpesvirus vBCL-2s block apoptosis induced by deregulated c-myc (Fanidi et al. 1998), a contributing factor to many cancers including Burkitt's lymphoma (Rickinson and Kieff 2001). Expression of the herpesvirus v-cyclin, which is required for reemergence from latency, induces S-phase entry and apoptosis, and its expression is oncogenic (Ojala et al. 1999, 2000; Van Dyk et al. 1999). Inhibition of apoptosis mediated by death receptors and their ligands such as TRAIL is also inhibited by vBCL-2s, and TRAIL-deficient mice are tumor prone (Cretney et al. 2002). Thus, many of the critical molecular events required for conversion of a normal cell to a tumor cell are functions of viral transforming proteins. As viral proteins are homologs of deregulated cellular proteins, they represent unique targets for anticancer drug discovery.

\section{Acknowledgments}

The authors thank D. Nelson, R. Sundararajan, D. Perez, and K. Degenhardt for critical reading of the manuscript, and Thomasina Sharkey for assistance with preparation of the manuscript. This work was funded by NCI grants R37-CA53370 and RO1 CA60088, and the Howard Hughes Medical Institute.

\section{References}

Afonso, C.L., Neilan, J.G., Kutish, G.F., and Rock, D.L. 1996. An African swine fever virus Bcl-2 homolog, 5-HL, suppresses apoptotic cell death. J. Virol. 70: 4858-4863.

Afonso, C., Tulman, E., Lu, Z., Zsak, L., Kutish, G., and Rock, D. 2000. The genome of fowlpox virus. J. Virol. 74: 38153831.

Afonso, C.L., Tulman, E.R., Lu, Z., Zsak, L., Rock, D.L., and Kutish, G.F. 2001. The genome of turkey herpesvirus. J. Virol. 75: 971-978. 
Antoni, B.A., Sabbatini, P., Rabson, A.B., and White, E. 1995. Inhibition of apoptosis in human immunodeficiency virusinfected cells enhances virus production and facilitates persistent infection. J. Virol. 69: 2384-2392.

Antonsson, B., Montessuit, S., Lauper, S., Eskes, R., and Martinou, J.-C. 2000. Bax oligomerization is required for channelforming activity in liposomes and to trigger cytochrome $c$ release from mitochondria. Biochemistry 345: 271-278.

Aritomi, M., Kunishima, N., Inohara, N., Ishibashi, Y., Ohta, S., and Morikawa, K. 1997. Crystal structure of rat Bcl- $\mathrm{x}_{\mathrm{L}}$. Implications for the function of the Bcl-2 protein family. J. Biol. Chem. 272: 27886-27892.

Barry, M. and McFadden, G. 1998. Apoptosis regulators from DNA viruses. Curr. Opin. Immunol. 10: 422-430.

Bellows, D.S., Chau, B.N., Lee, P., Lazebnik, Y., Burns, W.H., and Hardwick, J.M. 2000. Antiapoptotic herpesvirus Bcl-2 homologs escape caspase-mediated conversion to proapoptotic proteins. J. Virol. 74: 5024-5031.

Bellows, D.S., Howell, M., Pearson, C., Hazlewood, S.A., and Hardwick, J.M. 2002. Epstein-Barr virus BALF1 is a BCL-2like antagonist of the herpesvirus antiapoptotic BCL-2 proteins. J. Virol. 76: 2469-2479.

Boyd, J., Malstrom, S., Subramanian, T., Venkatesh, L., Schaeper, U., Elangovan, B., D'Sa-Eipper, C., and Chinnadurai, G. 1994. Adenovirus E1B $19 \mathrm{kDa}$ and bcl-2 proteins interact with a common set of cellular proteins. Cell 79: 341-351.

Boyd, J.M., Gallo, G.J., Elangovan, B., Houghton, A.B., Malstrom, S., Avery, S.J., Ebb, R.G., Subramanian, T., Chittenden, T., Lutz, R.J., et al. 1995. Bik1, a novel death-inducing protein shares a distinct sequence motif with Bcl-2 family proteins and interacts with viral and cellular survival-promoting proteins. Oncogene 11: 1921-1928.

Brun, A., Rivas, C., Esteban, M., Escribano, J.M., and Alonso, C. 1996. African swine fever virus gene $A 179 L$, a viral homolog of $b c l-2$, protects cells from programmed cell death. Virology 225: 227-230.

Brun, A., Rodriguez, F., Escribano, J.M., and Alonso, C. 1998. Functionality and cell anchorage dependence of the African swine fever virus gene $A 179 L$, a viral bcl-2 homolog, in insect cells. J. Virol. 72: 10227-10233.

Carracosa, A., Bustos, M.J., Nogal, M.L., Gonzalez de Buitrago, G., and Revilla, Y. 2002. Apoptosis induced in an early step of African swine fever virus entry into vero cells does not require virus replication. Virology 294: 372-382.

Chang, B.S., Minn, A.J., Muchmore, S.W., Fesik, S.W., and Thompson, C.B. 1997. Identification of a novel regulatory domain in Bcl-X $\mathrm{L}_{\mathrm{L}}$ and Bcl-2. EMBO J. 16: 968-977.

Cheevers, W.P., O'Callaghan, D.J., and Randall, C.C. 1968. Biosynthesis of host and viral deoxyribonucleic acid during hyperplastic fowlpox infection in vivo. J. Virol. 2: 421-429.

Chen, G., Branton, P.E., Yang, E., Korsmeyer, S.J., and Shore, G.C. 1996. Adenovirus E1B 19-kDa death suppressor protein interacts with Bax but not with Bad. J. Biol. Chem. 271: 24221-24225.

Cheng, E.H.-Y., Kirsch, D.G., Clem, R.J., Ravi, F., Kastan, M.B., Bedi, A., Ueno, K., and Hardwick, J.M. 1997a. Conversion of Bcl-2 to a Bax-like death effector by caspases. Science 278: 1966-1968.

Cheng, E.H.-Y., Nicholas, J., Bellows, D.S., Hayward, G.S., Guo, H.G., Reitz, M.S., and Hardwick, J.M. 1997b. A Bcl-2 homolog encoded by Kaposi sarcoma-associated virus, human herpes virus 8 , inhibits apoptosis but does not heterodimerize with Bax or Bak. Proc. Natl. Acad. Sci. 94: 690-694.

Cheng, E.H.-Y., Wei, M., Weiler, S., Flavell, R., Mak, T., Lindsten, T., and Korsmeyer, S. 2001. BCL-2, BCL- $\mathrm{X}_{\mathrm{L}}$ sequester
BH3 domain-only molecules preventing BAX- and BAK-mediated mitochondrial apoptosis. Mol. Cell 8: 705-711.

Chiou, S.-K. and White, E. 1998. Inhibition of ICE-like proteases inhibits apoptosis and increases virus production during adenovirus infection. Virology 244: 108-118.

Chiou, S.-K., Rao, L., and White, E. 1994a. Bcl-2 blocks p53dependent apoptosis. Mol. Cell. Biol. 14: 2556-2563.

Chiou, S.-K., Tseng, C.C., Rao, L., and White, E. 1994b. Functional complementation of the adenovirus E1B $19 \mathrm{~K}$ protein with Bcl-2 in the inhibition of apoptosis in infected cells. $J$. Virol. 68: 6553-6566.

Chittenden, T., Harrington, E.A., O'Connor, R., Flemington, C., Lutz, R.J., Evan, G.I., and Guild, B.C. 1995. Induction of apoptosis by the Bcl-2 homologue Bak. Nature 374: 733736.

Chou, J.J., Li, H., Salvesen, G.S., Yuan, J., and Wagner, G. 1999. Solution structure of BID, an intracellular amplifier of apoptotic signaling. Cell 96: 615-624.

Chu, Y., Sperber, K., Mayer, L., and Hsu, M.-T. 1992. Persistent infection of human adenovirus type 5 in human monocyte cell lines. Virology 188: 793-800.

Cleary, M.L., Smith, S.D., and Sklar, J. 1986. Cloning and structural analysis of cDNAs for bcl-2 and a hybrid bcl-2/immunoglobulin transcript resulting from the $t(14 ; 18)$ translocation. Cell 47: 19-28.

Cretney, E., Takeda, K., Yagita, H., Glaccum, M., Peschon, J.J., and Smyth, M.J. 2002. Increased susceptibility to tumor initiation and metastasis in TNF-related apoptosis-inducing ligand-deficient mice. J. Immunol. 168: 1356-1361.

Cuconati, A., Degenhardt, K., Sundararajan, R., Anschel, A., and White, E. 2002. BAK and BAX function to limit adenovirus replication through apoptosis induction. J. Virol. 76: 45474558.

Davis, J.E., Sutton, V.R., Smyth, M.J., and Trapani, J.A. 2000. Dependence of granzyme B-mediated cell death on a pathway regulated by Bcl-2 or its viral homolog, BHRF1. Cell Death Differ. 7: 973-983.

Debbas, M. and White, E. 1993. Wild-type p53 mediates apoptosis by E1A which is inhibited by E1B. Genes \& Dev. 7: $546-554$.

Degenhardt, K., Sundararajan, R., Lindsten, T., Thompson, C.B., and White, E. 2002. Bax and Bak independently promote cytochrome-c release from mitochondria. J. Biol. Chem. 277: 14127-14134.

Derfuss, T., Fickenscher, H., Kraft, M.S., Henning, G., Lengenfelder, D., Fleckenstein, B., and Meinl, E. 1998. Antiapoptotic activity of the Herpesvirus saimiri-encoded bcl-2 homolog: Stabilization of mitochondria and inhibition of caspase-3-like activity. J. Virol. 72: 5897-5904.

Eskes, R., Desagher, S., Antonsson, A., and Martinou, J. 2000. Bid induces the oligomerization and insertion of Bax into the outer mitochondrial membrane. Mol. Cell. Biol. 20: 929935.

Fanidi, A., Hancock, D.C., and Littlewood, T.D. 1998. Suppression of c-Myc-induced apoptosis by the Epstein-Barr virus gene product BHRF1. J. Virol. 72: 8392-8395.

Farrow, S.N., White, J.H.M., Martinou, I., Raven, T., Pun, K.-T., Grinham, C.J., Martinou, J.-C., and Brown, R. 1995. Cloning of a bcl-2 homologue by interaction with adenovirus E1B 19K. Nature 374: 731-733.

Flomenberg, P., Piaskowski, V., Harb, J., Segura, A., and Casper, T. 1996. Spontaneous, persistent infection of a B-cell lymphoma with adenovirus. J. Med. Virol. 48: 267-272.

Foghsgaard, L. and Jäättelä, M. 1997. The ability of BHRF1 to inhibit apoptosis is dependent on stimulus and cell type. $J$. Virol. 71: 7509-7517. 
Gangappa, S., Van Dyk, L., Jewett, T., Speck, S., and Virgin IV, H. 2002. Identification of the in vivo role of a viral bcl-2. $J$. Exp. Med. 195: 931-940.

Gazit, E., LaRocca, P., Sansom, M.S.P., and Shai, Y. 1998. The structure and organization within the membrane of the helices composing the pore-forming domain of Bacillus thuringiensis $\delta$-endotoxin are consistent with an "umbrellalike" structure of the pore. Proc. Natl. Acad. Sci. 95: 1228912294.

Gerber, D. and Shai, Y. 2000. Insertion and organization within membranes of the $\delta$-endotoxin pore-forming domain, helix 4-loop-helix 5, and inhibition of its activity by a mutant helix 4 peptide. J. Biol. Chem. 275: 2360223607.

Gilbert, R.J., Jimenez, J.L., Chen, S., Tickle, I.J., Rossjohn, J., Parker, M., Andrew, P., and Saibil, H. 1999. Two structural transitions in membrane pore formation by pneumolysin, the pore-forming toxin of Streptococcus pneumoniae. Cell 97: 647-655.

Gomez-Villamandos, J.C., Hervas, J., Mendez, A., Carrasco, L., Martin de las Mulas, J., Villeda, C.J., Wilkinson, P.J., and Sierra, M.A. 1995. Experimental African swine fever: Apoptosis of lymphocytes and virus replication in other cells. $J$. Gen. Virol. 76: 2399-2405.

Gooding, L.R., Aquino, L., Duerksen-Hughes, P.J., Day, D., Horton, T.M., Yei, S., and Wold, W.S.M. 1991. The E1B-19K protein of group $\mathrm{C}$ adenoviruses prevents cytolysis by tumor necrosis factor of human cells but not mouse cells. J. Virol. 65: 3083-3094.

Gross, A., McDonnell, J.M., and Korsmeyer, S.J. 1999a. BCL-2 family members and the mitochondria in apoptosis. Genes \& Dev. 13: 1899-1911.

Gross, A., Yin, X.-M., Wang, K., Wei, M.C., Jockel, J., Milliman, C., Erdjument-Bromage, H., Tempst, P., and Korsmeyer, S.J. 1999b. Caspase cleaved BID targets mitochondria and is required for cytochrome $c$ release, while BCL- $\mathrm{X}_{\mathrm{L}}$ prevents this release but not tumor necrosis factor-R1/Fas death. J. Biol. Chem. 274: 1156-1163.

Haldar, S., Jena, N., and Croce, C. 1995. Inactivation of Bcl-2 by phosphorylation. Proc. Natl. Acad. Sci. 92: 4507-4511.

Han, J., Sabbatini, P., Perez, D., Rao, L., Modha, D., and White, E. 1996a. The E1B 19K protein blocks apoptosis by interacting with and inhibiting the p53-inducible and death-promoting Bax protein. Genes \& Dev. 10: 461-477.

Han, J., Sabbatini, P., and White, E. 1996b. Induction of apoptosis by human Nbk/Bik, a $\mathrm{BH} 3$-containing protein that interacts with E1B $19 \mathrm{~K}$ interacting protein. Mol. Cell. Biol. 16: $5857-5864$.

Han, J., Modha, D., and White, E. 1998a. Interaction of E1B 19K with Bax is required to block Bax-induced loss of mitochondrial membrane potential and apoptosis. Oncogene 17: 2993-3005.

Han, J., Wallen, H.D., Nuñez, G., and White, E. 1998b. E1B 19,000 molecular-weight protein interacts with and inhibits CED-4-dependent, FLICE-mediated apoptosis. Mol. Cell. Biol. 18: 6052-6062.

Hashimoto, S., Ishii, A., and Yonehara, S. 1991. The E1B oncogene of adenovirus confers cellular resistance to cytotoxicity of tumor necrosis factor and monoclonal anti-Fas antibody. Intl. Immunol. 3: 343-351.

Henderson, S., Huen, D., Rowe, M., Dawson, C., Johnson, G., and Rickinson, A. 1993. Epstein-Barr virus-coded BHRF1 protein, a viral homologue of $\mathrm{Bcl}-2$, protects human B cells from programmed cell death. Proc. Natl. Acad. Sci. 90: 8479-8483.

Henry, H., Thomas, A., Shen, Y., and White, E. 2002. Regulation of the mitochondrial checkpoint in p53-mediated apoptosis confers resistance to cell death. Oncogene 21: 748-760.

Hoge, A.T., Hendrickson, S.B., and Burns, W.H. 2000. Murine gammaherpesvirus 68 cyclin D homolog is required for efficient reactivation from latency. J. Virol. 74: 7016-7023.

Horwitz, M. 2001. Adenoviruses. In Fields virology (eds. D.M. Knipe et al.), pp. 2301-2326. Lippincott Williams \& Wilkins, Philadelphia.

Hsu, Y.-T. and Youle, R.J. 1997. Nonionic detergents induce dimerization among members of the Bcl-2 family. J. Biol. Chem. 272: 13829-13834.

- 1998. Bax in murine thymus is a soluble monomeric protein that displays differential detergent-induced conformations. J. Biol. Chem. 273: 10777-10783.

Huang, Q., Petros, A.M., Virgin, H.W., Fesik, S.W., and Olejniczak, E.T. 2002. Solution structure of a Bcl-2 homolog from Kaposi sarcoma virus. Proc. Natl. Acad. Sci. 99:34283433.

Kasof, G.M., Rao, L., and White, E. 1998. Btf: A novel deathpromoting transcriptional repressor that interacts with Bcl-2 related proteins. Mol. Cell. Biol. 19: 4390-4404.

Kawanishi, M. 1997. Epstein-Barr virus BHRF1 protein protects intestine 407 epithelial cells from apoptosis induced by tumor necrosis factor $\alpha$ and anti-Fas antibody. J. Virol. 71: 3319-3322.

Khanim, F., Dawson, C., Meseda, C.A., Dawson, J., Mackett, M., and Young, L.S. 1997. BHRF1, a viral homologue of the $\mathrm{Bcl}-2$ oncogene, is conserved at both the sequence and functional level in different Epstein-Barr virus isolates. J. Gen. Virol. 78: 2987-2999.

Kiefer, M.C., Brauer, M.J., Powers, V.C., Wu, J.J., Umansky, S.R., Tomei, L.D., and Barr, P.J. 1995. Modulation of apoptosis by the widely distributed Bcl-2 homologue Bak. Nature 374: 736-739.

Kieff, E. and Rickinson, A.B. 2001. Epstein-Barr virus and its replication. In Fields virology (eds. D.M. Knipe et al.), pp. 2511-2573. Lippincott Williams \& Wilkins, Philadelphia.

Korsmeyer, S.J., Wei, M.C., Saito, M., Weiler, S., Oh, K.J., and Schlesinger, P.H. 2000. Pro-apoptotic cascade activates BID, which oligomerizes BAK or BAX into pores that result in the release of cytochrome C. Cell Death Differ. 7: 1166-1173.

Lee, M.A. and Yates, J.L. 1992. BHRF1 of Epstein-Barr virus, which is homologous to human proto-oncogene bcl2, is not essential for transformation of B cells or for virus replication in vitro. J. Virol. 66: 1899-1906.

Levine, B., Huang, Q., Isaacs, J.T., Reed, J.C., Griffin, D.E., and Hardwick, J.M. 1993. Conversion of lytic to persistent $\alpha$ virus infection by the bcl-2 cellular oncogene. Nature 361: 739-742.

Li, H., Zhu, H., Xu, C.-J., and Yuan, J. 1998. Cleavage of BID by caspase 8 mediates the mitochondrial damage in the Fas pathway of apoptosis. Cell 94: 491-501.

Lindsten, T., Ross, A.J., King, A., Zong, W.-X., Rathmell, J.C., Shiels, H.A., Ulrich, E., Waymire, K.G., Mahar, P., Frauwirth, K., et al. 2000. The combined functions of the proapoptotic Bcl-2 family members, Bak and Bax, are essential for the normal development of multiple tissues. Mol. Cell 6: 1389-1399.

Luo, X., Budihardjo, I., Zou, H., Slaughter, C., and Wang, X. 1998. Bid, a Bcl2 interacting protein, mediates cytochrome $c$ release from mitochondria in response to activation of cell surface death receptors. Cell 94: 481-490.

Manoj, K.A.S. and Aronson, A.I. 1999. Analysis of mutations in the pore-forming region essential for insecticidal activity of a Bacillus thuringiensis $\delta$-endotoxin. J. Bacteriol. 181: 61036107. 
Marchini, A., Tomkinson, B., Cohen, J.I., and Kieff, E. 1991. BHRF1, the Epstein-Barr virus gene with homology to Bcl2, is dispensable for B-lymphocyte transformation and virus replication. J. Virol. 65: 5991-6000.

Marshall, W.L., Yim, C., Gustafson, E., Graf, T., Sage, D.R., Hanify, K., Williams, L., Fingeroth, J., and Finberg, R.W. 1999. Epstein-Barr virus encodes a novel homolog of the bcl-2 oncogene that inhibits apoptosis and associates with Bax and Bak. J. Virol. 73: 5181-5185.

McCarthy, N.J., Hazlewood, S.A., Huen, D.S., Rickinson, A.B., and William, G.T. 1996. The Epstein-Barr virus gene BHRF1, a homologue of the cellular oncogene Bcl-2, inhibits apoptosis induced by $\gamma$ radiation and chemotherapeutic drugs. In Mechanisms of lymphocyte activation and immune regulation (eds. S. Gupta and J.J. Cohen), pp. 83-97. Plenum Press, New York.

McCormick, F. 2001. Cancer gene therapy: Fringe or cutting edge? Nat. Rev. Cancer 1: 130-141.

McDonnell, J.M., Fushman, D., Milliman, C.L., Korsmeyer, S.J., and Cowburn, D. 1999. Solution structure of the proapoptotic molecule BID: A structural basis for apoptotic agonists and antagonists. Cell 96: 625-634.

McGlade, C.J., Tremblay, M.L., Yee, S.-P., Ross, R., and Branton, P.E. 1987. Acylation of the 176R (19-kilodalton) early region 1B protein of human adenovirus type 5. I. Virol. 61: 3227-3234.

McGlade, C.J., Tremblay, M.L., and Branton, P.E. 1989. Mapping of a phosphorylation site in the $176 \mathrm{R}(19 \mathrm{kDa})$ early region $1 \mathrm{~B}$ protein of human adenovirus type 5. Virology 168: 119-127.

Meseda, C.A., Arrand, J.R., and Mackett, M. 2000. Herpesvirus papio encodes a functional homologue of the Epstein-Barr virus apoptosis suppressor, BHRF-1. J. Gen. Virol. 81: 18011805.

Moore, P.S. and Chang, Y. 2001. Kaposi's sarcoma-associated herpesvirus. In Fields virology (eds. D.M. Knipe et al.), pp. 2803-2833. Lippincott Williams \& Wilkins, Philadelphia.

Moss, B. 2001. Poxviridae: The viruses and their replication. In Fields virology (eds. D.M. Knipe et al.), pp. 2849-2883. Lippincott Williams \& Wilkins, Philadelphia.

Muchmore, S.W., Sattler, M., Liang, H., Meadows, R.P., Harlan, J.E., Yoon, H.S., Nettesheim, D., Chang, B.S., Thompson, C.B., Wong, S.-L., et al. 1996. X-Ray and NMR structure of human Bcl- $\mathrm{x}_{\mathrm{L}}$, an inhibitor of programmed cell death. $\mathrm{Na}$ ture 381: 335-341.

Nava, V.E., Cheng, E.H.-Y., Veliuona, M., Zou, S., Clem, R.J., Mayer, M.L., and Hardwick, M. 1997. Herpesvirus saimiri encodes a functional homolog of the human $b c l-2$ oncogene. J. Virol. 71: 4118-4122.

Neilan, J.G., Lu, Z., Afonzo, C.L., Kutish, G.F., Sussman, M.D., and Rock, D.L. 1993. An African swine fever virus gene with similarity to the proto-oncogene $b c l-2$ and the Epstein-Barr virus gene BHRF1. J. Virol. 67: 4391-4394.

Nicholas, J., Ruvolo, V., Zong, J., Ciufo, D., Guo, H.-G., Reitz, M.S., and Hayward, G.S. 1997. A single 13-kilobase divrgent locus in the Kaposi sarcoma-associated herpesvirus (human herpesvirus 8) genome contains nine open reading frames that are homologous to or related to cellular proteins. J. Virol. 71: 1963-1974.

Ojala, P.M., Tiainen, M., Salven, P., Veikkola, T., CastanosVelez, E., Sarid, R., Biberfeld, P., and Makela, T.P. 1999. Kaposi's sarcoma-associated herpesvirus-encoded v-cyclin triggers apoptosis in cells with high levels of cyclin-dependent kinase 6. Cancer Res. 59: 4984-4989.

Ojala, P.M., Yamamoto, K., Castanos-Velez, E., Biberfeld, P.,
Korsmeyer, S.J., and Makela, T.P. 2000. The apoptotic vcyclin-CDK6 complex phosphorylates and inactivates Bcl-2. Nat. Cell Biol. 2: 819-825.

Oltvai, Z.N., Millman, C.L., and Korsmeyer, S.J. 1993. Bcl-2 heterodimerizes in vivo with a conserved homolog, Bax, that accelerates programmed cell death. Cell 74: 609-619.

Oura, C.A.L., Powell, P.P., and Parkhouse, R.M.E. 1998. African swine fever: A disease characterized by apoptosis. J. Gen. Virol. 79: 1427-1438.

Perez, D. and White, E. 1998. E1B 19K inhibits Fas-mediated apoptosis through FADD-dependent sequestration of FLICE. J. Cell Biol. 141: 1255-1266.

. 2000. TNF- $\alpha$ signals apoptosis through a Bid-dependent conformational change in Bax that is inhibited by E1B $19 \mathrm{~K}$ Mol. Cell 6: 53-63.

Petros, A.M., Medek, A., Nettesheim, D.G., Kim, D.H., Yoon, H.S., Swift, K., Matayoshi, E.D., Oltersdorf, T., and Fesik, S.W. 2001. Solution structure of the antiapoptotic protein bcl-2. Proc. Natl. Acad. Sci. 98: 3012-3017.

Pilder, S., Logan, J., and Shenk, T. 1984. Deletion of the gene encoding the adenovirus 5 early region 1B 21,000-molecular weight polypeptide leads to degradation of viral and cellular DNA. J. Virol. 52: 664-671.

Querido, E., Blanchette, P., Yan, Q., Kamura, T., Morrison, M., Boivin, D., Kaelin, W., Conaway, R., Conaway, J.W., and Branton, P.E. 2001. Degradation of p53 by adenovirus E4 orf6 and E1B $55 \mathrm{~K}$ proteins occurs via a novel mechanism involving a Cullin-containing complex. Genes \& Dev. 15: 31043117.

Rabizadeh, S., LaCount, D.J., Friesen, P.D., and Bredesen, D.E. 1993. Expression of the baculovirus p35 gene inhibits mammalian neuronal cell death. J. Neurochem. 61: 23182321.

Ramiro-Ibanez, F., Ortega, A., Brun, A., Escribano, J.M., and Alonso, C. 1996. Apoptosis: A mechanism of cell killing and lymphoid organ impairment during acute African swine fever virus infection. J. Gen. Virol. 77: 2209-2219.

Rao, L., Debbas, M., Sabbatini, P., Hockenberry, D., Korsmeyer, S., and White, E. 1992. The adenovirus E1A proteins induce apoptosis which is inhibited by the E1B $19 \mathrm{~K}$ and Bcl-2 proteins. Proc. Nat1. Acad. Sci. 89: 7742-7746.

Rao, L., Modha, D., and White, E. 1997. The E1B 19K protein associates with lamins in vivo and its proper localization is required for inhibition of apoptosis. Oncogene 15: $1587-1597$.

Revilla, Y., Cebrian, A., Baixeras, E., Martinez-A, C., Vinuela, E., and Salas, M.L. 1997. Inhibition of apoptosis by the African swine fever virus Bcl-2 homologue: Role of the BH1 domain. Virology 228: 400-404.

Rickinson, A.B. and Kieff, E. 2001. Epstein-Barr virus. Lippincott Williams \& Wilkins, Philadelphia.

Rivailler, P., Jiang, H., Cho, Y.-G., Quink, C., and Wang, F. 2002. Complete nucleotide sequence of the rhesus lymphocryptovirus: Genetic validation for an Epstein-Barr virus animal model. J. Virol. 76: 421-426.

Roizman, B. and Pellett, P. 2001. The family herpesviridae: A brief introduction. In Fields virology (eds. D.M. Knipe et al.), pp. 2381-2397. Lippincott Williams \& Wilkins, Philadelphia.

Roulston, A., Marcellus, R.C., and Branton, P.E. 1999. Viruses and apoptosis. Annu. Rev. Microbiol. 53: 577-628.

Russo, J.J., Bohenzky, R.A., Chien, M.-C., Chen, J., Yan, M., Maddalena, D., Parry, J.P., Peruzzi, D., Edelman, I.S., Chang, Y., et al. 1996. Nucleotide sequence of the Kaposi sarcomaassociated herpesvirus (HHV8). Proc. Natl. Acad. Sci. 93: $14862-14867$. 
Sabbatini, P., Chiou, S.-K., Rao, L., and White, E. 1995. Modulation of p53-mediated transcriptional repression and apoptosis by the adenovirus E1B 19K protein. Mol. Cell. Biol. 15: 1060-1070.

Sarid, R., Sato, T., Bohenzky, R.A., Russo, J.J., and Chang, R.Y. 1997. Kaposi's sarcoma-associated herpesvirus encodes a functional Bcl-2 homologue. Nat. Med. 3: 293-309.

Sattler, M., Liang, H., Nettesheim, D., Meadows, R.P., Harlan, J.E., Eberstadt, M., Yoon, H.S., Shuker, S.B., Chang, B.S., Minn, A.J., et al. 1997. Structure of Bcl- $\mathrm{x}_{\mathrm{L}}-\mathrm{Bak}$ peptide complex: Recognition between regulators of apoptosis. Science 275: 983-986.

Shenk, T. 2001. Adenoviridae: The viruses and their replication. In Fields virology (eds. D.M. Knipe et al.), pp. 2265-2300. Lippincott Williams \& Wilkins, Philadelphia.

Shi, Y. 2002. Mechanisms of caspase activation and inhibition during apoptosis. Mol. Cell 9: 459-470.

Subramanian, T., Kuppuswamy, M., Gysbers, J., Mak, S., and Chinnadurai, G. 1984. 19-kDa tumor antigen coded by early region E1b of adenovirus 2 is required for efficient synthesis and for protection of viral DNA. J. Biol. Chem. 259: $11777-$ 11783.

Subramanian, T., Tarodi, B., and Chinnadurai, G. 1995. p53independent apoptotic and necrotic cell deaths induced by adenovirus infection: Suppression by E1B 9K and Bcl-2 proteins. Cell Growth Differ. 6: 131-137.

Sundararajan, R. and White, E. 2001. E1B 19K blocks Bax oligomerization and tumor necrosis factor $\alpha$-mediated apoptosis. J. Virol. 75: 7506-7516.

Sundararajan, R., Cuconati, A., Nelson, D., and White, E. 2001. Tumor necrosis factor- $\alpha$ induces Bax-Bak interaction and apoptosis, which is inhibited by adenovirus E1B 19K. J. Biol. Chem. 276: 45120-45127.

Suzuki, M., Youle, R.J., and Tjandra, N. 2000. Structure of Bax: Coregulation of dimer formation and intracellular localization. Cell 103: 645-654.

Takemori, N., Cladaras, C., Bhat, B., Conley, A.J., and Wold, W.S.M. 1984. cyt gene of adenovirus 2 and 5 is an oncogene for transforming function in early region E1B and encodes the E1B 19,000-molecular-weight polypeptide. I. Virol. 52: 793-805.

Tarodi, B., Subramanian, T., and Chinnadurai, G. 1993. Functional similarity between adenovirus E1B 19K gene and Bcl-2 oncogene: Mutant complementation and suppression of cell death induced by DNA damaging agents. Intl. I. Oncol. 3: 467-472.

. 1994. Epstein-Barr virus BHRF1 protein protects against cell death induced by DNA-damaging agents and heterologous viral infection. Virology 201: 404-407.

Theodorakis, P., D'Sa-Eipper, C., Subramanian, T., and Chinnadurai, G. 1996. Unmasking of a proliferation-restraining activity of the anti-apoptosis protein EBV BHRF1. Oncogene 12: $1707-1713$.

Tollefson, A.E., Scaria, A., Hermiston, T.W., Ryerse, J.S., Wold, L.J., and Wold, W.S.M. 1996. The adenovirus death protein (E3-11.6K) is required at very late stages of infection for efficient cell lysis and release of adenovirus from infected cells. J. Virol. 70: 2296-2306.

Tollefson, A., Toth, K., Doronin, K., Kuppuswamy, M., Doronina, O., Lichtenstein, D., Hermiston, T., Smith, C., and Wold, W. 2001. Inhibition of TRAIL-induced apoptosis and forced internalization of TRAIL-receptor 1 by adenovirus proteins. J. Virol. 75: 8875-8877.

Uhlmann, E.J., D'Sa-Eipper, C., Subramanian, T., Wagner, A.J., Hay, N., and Chinnadurai, G. 1996. Deletion of a nonconserved region of Bcl-2 confers a novel gain of function: Sup- pression of apoptosis with concomitant cell proliferation. Cancer Res. 56: 2506-2509.

Van Der Veen, J. and Lambriex, M. 1973. Relationship of adenovirus to lymphocytes in naturally infected human tonsils and adenoids. Infect. Immun. 7: 604-609.

Van Dyk, L.F., Hess, J.L., Katz, J.D., and Jacoby, M. 1999. The murine gammaherpesvirus $68 \mathrm{v}$-cyclin gene is an oncogene that promotes cell cycle progression in primary lymphocytes. J. Virol. 73: 5110-5122.

Van Dyk, L.F., Virgin IV, H.W., and Speck, S.H. 2000. The murine gammaherpesvirus $68 \mathrm{v}$-cyclin is a critical regulator of reactivation from latency. J. Virol. 74: 7451-7461.

Vaux, D.L., Cory, S., and Adams, T.M. 1988. Bcl-2 promotes the survival of haemopoietic cells and cooperates with c-myc to immortalize pre-B cells. Nature 335: 440-442.

Virgin IV, H., Latreille, P., Wamsley, P., Hallsworth, K., Weck, K., Dal Canto, A.J., and Speck, S.H. 1997. Complete sequence and genomic analysis of murine gammaherpesvirus 68. J. Virol. 71: 5894-5904.

Vorburger, S.J. and Hunt, K.K. 2002. Adenoviral gene therapy. Oncologist 7: 46-59.

Wallace, A., Stillman, T., Atkins, A., Jamieson, S.J., Bullough, P.A., Green, J., and Artymiuk, P.J. 2000. E. coli hemolysis E (HlyE, ClyA, SheA): X-Ray crystal structure of the toxin and observation of membrane pores by electron microscopy. Cell 100: $265-276$.

Wang, G.H., Garvey, T. L., and Cohen, J.I. 1999. The murine gammaherpesvirus-68 M11 protein inhibits Fas- and TNFinduced apoptosis. J. Gen. Virol. 80: 2737-2740.

Wang, X. 2001. The expanding role of mitochondria in apoptosis. Genes \& Dev. 15: 2922-2933.

Wei, M.C., Lindsten, T., Mootha, V.K., Weiler, S., Gross, A., Ashiya, M., Thompson, C.B., and Korsmeyer, S.J. 2000. tBid, a membrane-targeted death ligand, oligomerizes Bak to release cytochrome c. Genes \& Dev. 14: 2060-2071.

Wei, M., Zong, W.-X., Cheng, E., Lindsten, T., Panoutsakopoulou, V., Ross, A., Roth, K., MacGregor, G., Thompson, C., and Korsmeyer, S. 2001. Proapoptotic Bax and Bak: A requisite gateway to mitochondrial dysfunction and death. Science 292: 727-730.

White, E. 1994. Function of the adenovirus E1B oncogene in infected and transformed cells. Sem. Virol. 5: 341-348.

- 2001. Regulation of the cell cycle and apoptosis by the oncogenes of adenovirus. Oncogene 20: 7836-7846.

White, E., Grodzicker, T., and Stillman, B.W. 1984. Mutations in the gene encoding the adenovirus E1B 19K tumor antigen cause degradation of chromosomal DNA. J. Virol. 52: 410-419.

White, E., Cipriani, R., Sabbatini, P., and Denton, A. 1991. The adenovirus E1B 19-kilodalton protein overcomes the cytotoxicity of E1A proteins. J. Virol. 65: 2968-2978.

White, E., Sabbatini, P., Debbas, M., Wold, W.S.M., Kusher, D.I., and Gooding, L. 1992. The 19-kilodalton adenovirus E1B transforming protein inhibits programmed cell death and prevents cytolysis by tumor necrosis factor $\alpha$. Mol. Cell. Biol. 12: 2570-2580.

Wold, W.S.M., Doronin, K., Toth, K., Kuppuswamy, M., Lichtenstein, D.L., and Tollefson, A.E. 1999. Immune responses to adenoviruses: Viral evasion mechanisms and their implications for the clinic. Curr. Opin. Immunol. 11: 380-386.

Yanez, R.J., Rodriguez, J.M., Nogal, M.L., Yuste, L., Enriquez, C., Rodriguez, J.F., and Vinuela, E. 1995. Analysis of the complete nucleotide sequence of African swine fever virus. Virology 208: 249-278.

Zong, W.-X., Lindsten, T., Ross, A.J., MacGregor, G.R., and Thompson, C.B. 2001. BH3-only proteins that bind pro-survival Bcl-2 family members fail to induce apoptosis in the absence of Bax and Bak. Genes \& Dev. 15: 1481-1486. 


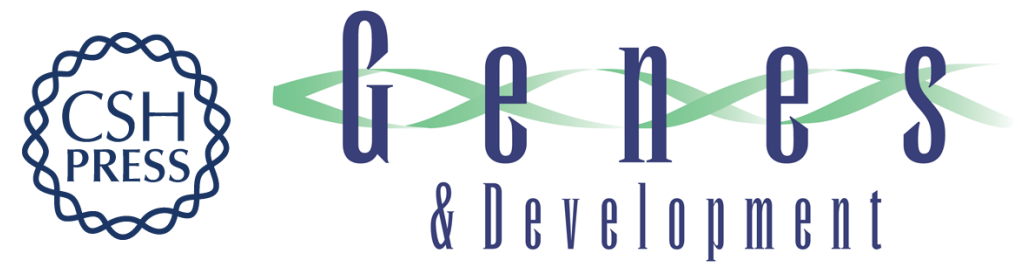

\section{Viral homologs of BCL-2: role of apoptosis in the regulation of virus infection}

Andrea Cuconati and Eileen White

Genes Dev. 2002, 16:

Access the most recent version at doi:10.1101/gad.1012702

References This article cites 131 articles, 78 of which can be accessed free at: http://genesdev.cshlp.org/content/16/19/2465.full.html\#ref-list-1

License

Email Alerting

Receive free email alerts when new articles cite this article - sign up in the box at the top Service right corner of the article or click here.

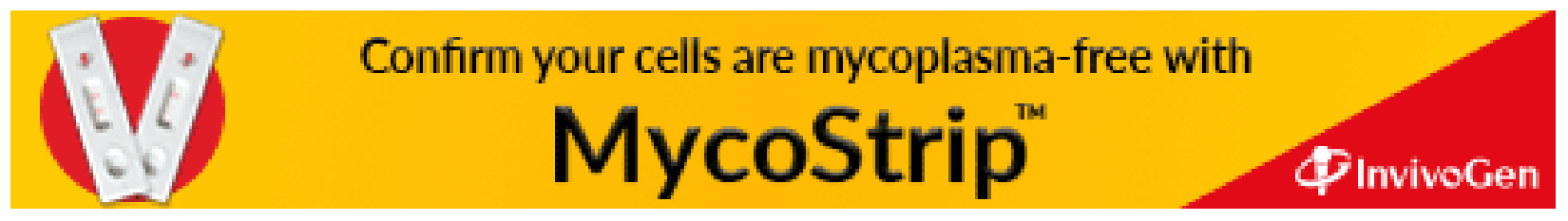

